\title{
Incidence of Hypertension in Patients Undergoing Surgery at Dhulikhel Hospital - Kathmandu University Hospital.
}

\author{
Sapkota S, Sherpa M, Bhattarai B
}

Department of Anesthesia and Critical Care Medicine

Dhulikhel Hospital - Kathamndu University Hospital

Dhulikhel Hospital, Kavre, Nepal

\author{
Corresponding Author \\ Dr Basant Bhattarai \\ Department of Anesthesia and Critical Care Medicine \\ Dhulikhel Hospital, Kathmandu University Hospital \\ Dhulikhel, Kavre
}

Email:basantbhattarai@yahoo.com

Citation

Sapkota S, Sherpa M, Bhattarai B.Incidence of hypertension in patients undergoing surgery at Dhulikhel Hospital - Kathmandu University Hospital.. Kathmandu Univ Med J. 2011;34(2)40-3.

\begin{abstract}
Background

Hypertension is an important public health challenge worldwide and is most important modifiable risk factor for cardiovascular, cerebrovascular and renal disease. Blood pressure determination forms an integral part of anaesthesiologist's evaluation of hispatient's condition prior to and during surgery. Data are not available which indicate changes in blood pressure occurring preanaesthetically in hospitalized patients. There are several risks from untreated preoperative hypertension in perioperative and postoperative phase.
\end{abstract}

\section{Objective}

To know the incidence of hypertension in preoperative patients undergoing major surgery

\section{Methods}

This retrospective observational study was based on the data collected from preanaesthetic checkup record book from January 2010 to December 2010.

Results

A total of 955 patients were studied and analyzed in terms of hypertension and demographic characteristics. The total incidence of hypertension in preoperative phase was $10.16 \%$. Among them $64.9 \%$ being male and $35.1 \%$ female. Maximum incidence was found in age group 50-59 years i.e. $26.6 \%$. Among the case detected maximum patients i.e. $52 \%$ were patients with newly diagnosed hypertension and among those under medications $61.1 \%$ were using calcium channel blockers.

\section{Conclusion}

Knowing the incidence will help in proper preoperative optimization of the hypertensive patients and also help in decreasing the incidence of postoperative complications..

\section{KEY WORDS}

anaesthesia, calcium channel blockers, diuretics, hypertension,

\section{INTRODUCTION}

Hypertension is an important public health challenge worldwide. $^{1}$ Because of its high prevalence, there is concomitant increase in risk of other systemic disease. ${ }^{2}$ Hypertension can be defined as blood pressure of more than $140 / 90 \mathrm{~mm}$ of $\mathrm{Hg}^{3}$ It is the most important modifiable risk factor for cardiovascular, cerebrovascular and renal disease. The comparative Risk Assessment Collaborating Group has identified hypertension as the leading global risk factor for mortality and as the third leading risk factor for disease burden. ${ }^{4}$

It affects one billion people around the globe and is responsible for 7.1 million deaths per year. ${ }^{5}$ Observational studies involving more than one million individuals demonstrate that death from ischemic heart disease and stroke increases constantly as blood pressure increases from as low as $115 \mathrm{mmHg}$ systolic and $75 \mathrm{mmHg}$ diastolic. ${ }^{6}$ Significant numbers of individuals with hypertension are unaware of their condition and, among those with diagnosed hypertension, treatment is frequently inadequate. ${ }^{7}$ It is also frequently detected among patients undergoing preoperative evaluation for surgical procedures.

Blood pressure determination forms an integral part of anaesthesiologists' evaluation of his patients' condition prior to and during surgery. Despite this reliance on blood pressure, data are not available which indicate changes in blood pressure occurring preanaesthetically in hospitalized patients. Since the majority of elective surgical patients have only had single blood pressure determination made prior to arrival in the operating room, the question invariably arises as to the importance, if any, which should 
be attached to differences between preanaesthetic blood pressure recording and those recording previously obtained.

If a patient is truely found to have elevated blood pressure preoperatively, the possible risk from this can beconsidered in two phases-the anaesthetic and the postoperativeperiods. It is not unusual for a patient undergoinganaesthesia to have a fall in blood pressure duringinduction, followed by a pressor response and tachycardiawith intubation, stabilization of blood pressure andheart rate during anaesthesia, and another rise during awakening and extubation8. Thus it is important to know about the blood pressure status of patient undergoing any operation. The present study was hence instituted to obtain information on incidence of hypertension in preoperative patients.

Aims and objectives:

1. To find the incidence of hypertension among preoperative patients.

2. Incidence in relation to demographic profile of the patients.

3. Preoperative drug intervention if any.

\section{METHODS}

After obtaining approval from hospital ethical committee of Dhulikhel Hospital, Kathmandu University Hospital, retrospective study was done among patients undergoing various elective operative procedures under general anaesthesia and subarachnoid block.

Patients undergoing elective surgery, categorized as hypertensive based on JNC 7 classification or known hypertensive, with or without regular medication were included. Obstetric patients undergoing emergency surgery, patients undergoing emergency surgery, trauma patients and pateint with age below 30 years were excluded.

Patients were examined preoperatively. The blood pressure was measured day before surgery at the evening with the use of sphygmomanometer. All the recordings were made with patient at rest, not under the influence of smoking or caffeine. Patients with blood pressure of more than 140/90 $\mathrm{mm}$ of $\mathrm{Hg}$ were considered hypertensive and the already known cases were also included in the incidence. Along with the measurement, patient was asked about personal details, preexisting comorbid conditions and the use of regular medications. Any antihypertensive medication being used was continued preoperatively, exclusion criteria being cerebrovascular accidents, renal dysfunction and other comorbid illness. Statistical analysis was done by Statistical Package for social sciences (SPSS) V 11. for windows.

\section{RESULTS}

We analyzed 955 cases from January 2010 to December 2010. There were total of 955 files out of which there were 540 general surgical cases, 178 urological cases and 237 gynaecological cases.

Out of 955 patients 94 patients were hypertensive. The incidence of hypertension was $10.16 \%$ as a whole.

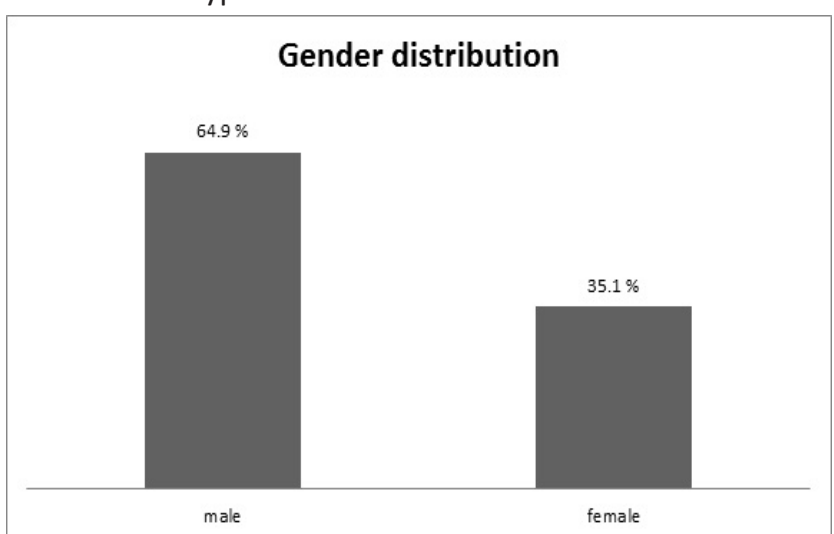

Figure 1. Gender distribution:

There were 61 (64.9\%) males and 33 (35.1\%) females, and the male-female ratio was 1.8:1. The mean age of the population was -58.04 years.

\section{age group distribution of the patients}

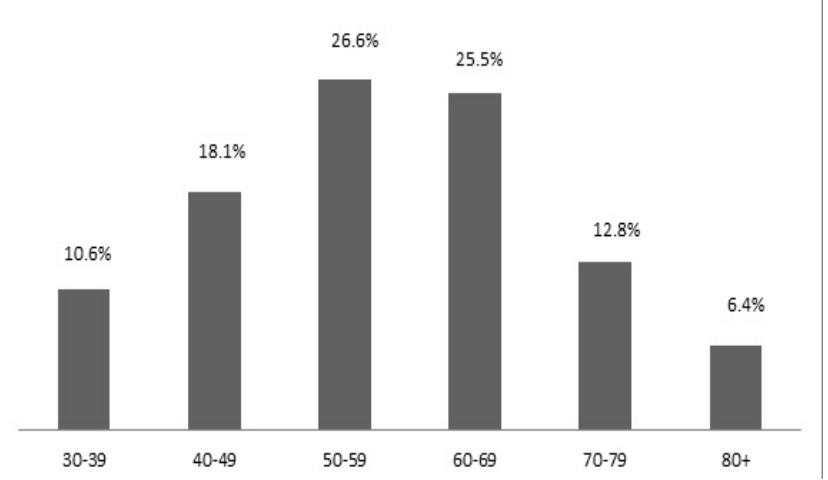

Figure 2. Age group distribution of the patients:

The incidence of hypertension was $10.6 \%$ in the age group $30-39,18.1 \%$ in the age group $40-49,26.6 \%$ in the age group $50-59,25.5 \%$ in the age group $60-69,12.8 \%$ in the age group $70-79,6.4 \%$ in the age group 80 and over.

Table 1. Geographical Distribution.

\begin{tabular}{ll} 
Districts & Number of patients (\%) \\
\hline Kavre & $56(59.6 \%)$ \\
\hline Sindhupalchok & $8(8.5 \%)$ \\
\hline Kathmandu & $8(8.5 \%)$ \\
\hline Bhaktapur & $11(11.7 \%)$ \\
\hline Others & $11(11.7 \%)$ \\
\hline
\end{tabular}

$59.6 \%$ patients in our study were from Kavre district, 8.5 $\%$ were from Sindhupalchok, $8.5 \%$ were from Kathmandu, $11.7 \%$ were from Bhaktapur and $11.7 \%$ were from other districts. 


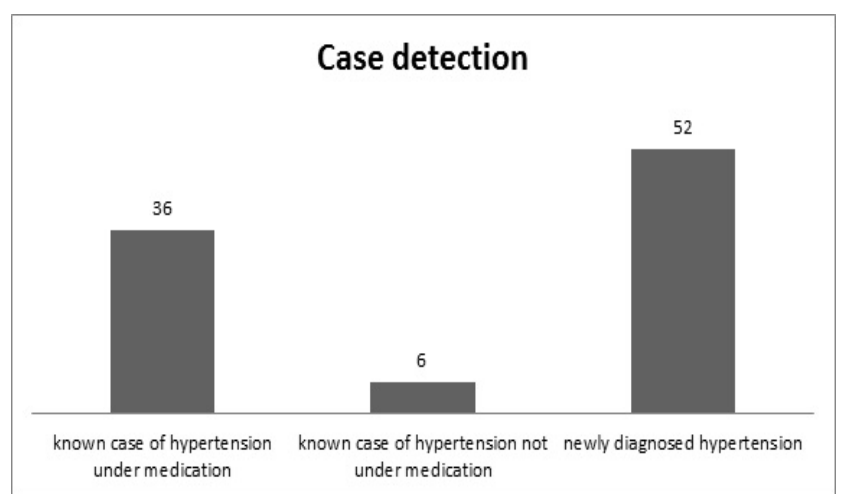

Figure 3. Case detection.

Of the total patients evaluated, 36 (38.3\%) patients were known case of hypertension under medication, 6 (6.4\%) patients were known case of hypertension not under any medication, 52 (55.3\%) were newly diagnosed cases of hypertension during preanaestheticcheckup.(Based on JNC 7 Guidelines)

Table 6. Medications used by known case of hypertension.

\begin{tabular}{|l|l|}
\hline Drugs & $\begin{array}{l}\text { Frequency (\%) } \\
5(13.9 \%)\end{array}$ \\
\hline BCE inhibitors & $5(13.9 \%)$ \\
Calcium channel blockers & $22(61.1 \%)$ \\
\hline Diuretics & $4(11.1 \%)$ \\
\hline
\end{tabular}

Of those who were taking regular medications, 5 (13.9\%) patients were taking ACE inhibitors, 5 (13.9\%) patients were taking beta blockers 22 (61.1 \%) patients were taking Calcium channel blockers and $4(11.1 \%)$ were taking diuretics.

\section{DISCUSSION}

Hypertension is an important public health challenge worldwide. Prevention, detection, treatment and control of it requires high priority. According to analysis of world wide data for global burden of hypertension, in $200026.4 \%$ of adult population were suffering from hypertension $(26.6 \%$ of men and $26.4 \%$ of female) and by 2025 , estimated $29.2 \%$ of total population will be suffering i.e., in 2000 total no of hypertensive patient were 972 million, 333million in economically developed and 639 million in economically developing countries and by 2025, 1.56 billion will be suffering from hypertension. ${ }^{7}$

As per study of anaesthesia, in relation to hypertension all of whom who had high arterial pressures before anaesthesia, severe decrease in arterial pressure occurred during anaesthesia and was associated with ECG evidence of MI. Baroreflex of heart rate was significantly decreased in hypertensive patient both before and during anaesthesia. It is concluded that untreated high arterial pressure constitutes a serious risk to patients undergoing anaesthesia and surgery, therefore it is of utmost importance to find out the blood pressure of patient in pre-operative phase. $^{9}$ In addition, chronic hypertension resets cerebral circulatory autoregulation so that in these patients intraoperative and postoperative blood pressure reductions to otherwise benign levels may induce cerebral ischemia. ${ }^{10}$

We had retrospectively analyzed 955 cases on the basis of preoperativeblood pressure and demographic profile. From the study $10.16 \%$ of the patients were found to be hypertensive in pre-operative phase. Male seemed predominantly more affected than female with the ratio being 1.8:1 coinciding with that of worldwide data 20007. Mean age suffering from hypertension was 58 years and age distribution maximum in 50-59 years unlike to that of worldwide data (2000) where maximum hypertension are and above $70 y e a r s$ in both male and female. This may have been attributed to the changes in lifestyle and ongoing urbanization in developing world.

Majority of hypertension was seen in patients from kavre followed by patients fromBhaktapur. Kavre being the local site and majority of patients coming to our hospital are from these places, this might have attributed to our result.

Major burden of hypertension in pre-operative cases were from general surgery (50\%) followed by urology. Nepal and worldwide based data were not available regarding this profile.Regarding case detection maximum were newly diagnosed hypertensive(52\%) followed by known case of hypertension under medications. Among those under medications majority were taking calcium channel blockers. Although JNC suggests to start on diuretics therapy, there has been trend in Nepal to use CCB as they are cheap and require less monitoring. These data are based on observation and not on any national consensus.

\section{CONCLUSION}

Hence total hypertensive patients in preoperative phase were $10.16 \%$ and if already known case they were advised to continue with their medications. Maximum used antihypertensive medication was calcium channel blocker followed by ACE inhibitors and betablockers.

Thus patients who undergo surgical procedures with their BP optimized have less serious hemodynamic changes in the intraoperative and postoperative period than patients with uncontrolled hypertension. ${ }^{9}$ If the surgical procedure is elective it should be postponed by few weeks until medical management occurs and is effective. ${ }^{11}$

Knowing the incidence will help in proper preoperative optimization of these patients and also help in decreasing the incidence of postoperative complications. 


\section{REFERENCES}

1. He J, Whelton PK. Epidemiology and prevention of hypertension.Med Clin North Am 1997; 81: 1077-97.

2. Whelton PK. Epidemiology of hypertension. Lancet 1994; 344:101-6.

3. The Seventh Report of the Joint National Committee on Prevention, Detection, Evaluation, and Treatment of High Blood Pressure.JAMA 2003;289:2560-71.

4. Ezzati M, Lopez AD, Rodgers A, Vander Hoorn S, Murray CJ.Selected major risk factors and global and regional burden of disease. Lancet 2002; 360: 1347-60.

5. Guilbert JJ. The World Health Report 2002: reducing risks, promoting healthy life. Educ Health (Abingdon) 2003; 16:230.

6. Lewington $\mathrm{S}$, Clarke R, Qizilbash $\mathrm{N}$, et al. Prospective Studies Collaboration. Age-specific relevance of usual blood pressure to vascular mortality: a metaanalysis of individual data for one million adults in 61 prospective studies. Lancet 2002; 360:1903-13.
7. Kearney PM, Whelton M, Reynolds K, Muntner P, Whelton PK, He J.Global burden of hypertension: analysis of worldwide data. Lancet 2005 Jan;365(9455):217-23.

8. Laslett L. Hypertension-Preoperative assessment and perioperative management. West J Med 1995; 162:215-9.

9. Prys-Roberts C, Meloche R, Foëx P. Studies of anaesthesia in relation to hypertension. Cardiovascular responses of treated and untreated patients. Br J Anaesth. 1971;43(2):122-37.

10. Strandgaard S: Autoregulation of cerebral blood flow in hypertensive patients. Circulation 1976; 53:720-7.

11. Magnusson J, Thulin T, Werner O, Jarhult J, Thomson D. Haemodynamic effects of pretreatment with metoprolol in hypertensive patients undergoing surgery. Br J Anaesth 1986; 58:251-60. 